\title{
Pore-Size Distribution in Collagen and Leather by the Porosimeter Method
}

\author{
Robert R. Stromberg
}

\begin{abstract}
The pore-size distribution in collagenous tissue and a number of leathers, in the range 100 to $20000-\mathrm{A}$ in radius, has been determined by means of a mercury-pressure porosimeter. The sources of error incurred in such measurements, the reliability of the measurements, and experimental and "actual" pore-size distributions are considered. The geometry of the fine and gross structure of leather, and the process of water-vapor transmission through leather are interpreted from the data.
\end{abstract}

\section{Introduction}

Collagenous tissue and the tanned product, leather, are natural polymeres that exhibit many unique properties. Some of these properties are believed to arise from the character of the matrix that is formed in nature by the fibrous network. For example, the enormous resistance to flexural fatigue exhibited by leather may be attributed to the ability of individual fibers to reorient under stress, thereby relieving the applied stress [1] ${ }^{1}$. Microscopically, the gross void volume occurring between fibers is quite apparent. Permeability measurements [2] and surface-area measurements $[3,4]$ have also provided substantiating evidence for a large pore volume.

This paper describes initial results of an investigation of the macropore-size distribution in collagen and leather, encompassing pores from approximately 100 to $20000-\mathrm{A}$ radius. With such information, additional understanding of the gross structure of collagen, such as the nature of the weave and the binding of the filaments, fibrils, primitive fibers, and fibers [5], would be provided. Some insight into such processes as water-vapor transmission and other processes of interest to leather technologists would also be provided.

The method used in this study to measure poresize distributions is based on the relationship pointed out by Washburn [6], that certain pressures are required to force a nonwetting liquid (mercury) into pores of certain radii. This equation is

$$
\operatorname{Pr}=-2 \sigma \cos \theta
$$

where $P$ is the pressure, $r$ is the pore radius, $\sigma$ is the surface tension of the liquid, and $\theta$ is the contact angle between the liquid and solid. The average contact angle of $140^{\circ}$ found by Ritter and Drake [7], and a surface tension of 480 dynes per centimeter are used in this study.

A cylindrical shape, having a circular cross section, is assumed for the pore. Constancy of surface tension and contact angle also are assumed. For a given value of $r$, there will be a unique value of $P$ leading to a characteristic pressure curve. The following tabulation shows the size of pores that will be filled

\footnotetext{
1 Figures in brackets indicate the literature references at the end of this paper.
}

with mercury at different pressures as calculated from eq (1):

\begin{tabular}{|r|r|}
\hline$P$ & \multicolumn{1}{c|}{$r$} \\
\cline { 2 - 2 }$p s i$ & \\
50 & $A$ \\
100 & 21300 \\
500 & 10700 \\
1,000 & 2100 \\
10,000 & 1100 \\
& 100 \\
\hline
\end{tabular}

Ritter and Drake $[7,8]$ developed the porosimeter method based on this relationship. Their method involved forcing a measured quantity of mercury under a known pressure into a previously prepared porous specimen. A distribution function, $D(r)$, was defined by Ritter and Drake as

$$
D(r)=d V / d r,
$$

where $d V$ is the total volume of all pores of radii between $r$ and $r+d r$. As the pressure rather than pore radius is measured, the relation given in eq (2) can be written

$$
D(r)=P / r(d V / d P) .
$$

The values of $d V / d p$ were obtained from the pressure curve by the method of secants.

An important source of error is involved in the assumption of a circular cross-sectional area used in the derivation of eq (1). Deviations from this assumed geometry will change the ratio of circumference to cross-sectional area and will affect the relationship between $P$ and $r$. The use of eq (1) gives a figure for the pore-entrance radius, which may be quite different from that along the remainder of the pore. However, it is assumed that the general nature of the cross-sectional area will not vary from one hide to another, and that only the constant will be in error. If this is so, the calculated radii will vary from the actual value of the radii by a constant factor, and only the absolute value of the radii will be in error, the relative values remaining unchanged. Intercomparisons of relative values should, therefore, be valid.

The possibility exists that pressure differences may crush or otherwise distort the pore structure. How- 
ever, measurements are made at steady-state conditions, and by increasing the hydrostatic pressure in comparatively small increments, no appreciable pressure differences should develop. Juhola and Wiig [9] demonstrated that at pressures up to 2,400 psi there was no destruction of pore structure in soft charcoals.

Another possible source of error lies in the assumption that the contact angle and surface tension are not pressure dependent. Joyner, Barrett, and Skold [10] compared the results obtained by using a nitrogen desorption isotherm [11] with the porosimeter method for bone chars, and obtained remarkable agreement, using a constant contact angle and surface tension. It appears, therefore, that this may not be a serious source of error.

The values of the contact angle and surface tension used in eq (1) would be affected by the properties of the surface of the capillary pore walls and any contamination of the mercury surface. The exact values used here are uncertain. Although an error in the values used for the contact angle and surface tension would shift the pore-size distribution curve, it is reasonable to assume that for similar materials measured under similar conditions, valid intercomparisons can be made.

\section{Materials Investigated}

The materials studied in this investigation are listed in table 1, along with the identity, thickness, and "dry" weight of each specimen. The thickness was measured with a standard dead-weight gage [12], and the dry weight was obtained after drying the specimens overnight in a forced-air oven maintained at $80^{\circ}$ C. Specimens 3 to 8 were obtained from a small area of a central location of one bend of vegetable-tanned crust leather. Only the first grain and flesh splits and the center of the corium section were used. The degreasing was accomplished by extraction with chloroform in a Soxhlet extraction apparatus.

Specimen 9 was prepared by dehydrating the wet cowhide by a solvent-exchange process. The wet

TABLE 1. Materials investigated

\begin{tabular}{|c|c|c|c|}
\hline $\begin{array}{l}\text { Speci- } \\
\text { men }\end{array}$ & Material & $\begin{array}{l}\text { Thick- } \\
\text { ness }\end{array}$ & $\begin{array}{c}\text { Dry } \\
\text { weight }\end{array}$ \\
\hline & & & \\
\hline & Vegetable-tanned finished sole leather . & 0.572 & 3. 2260 \\
\hline & Obtained from area adjoining specimen 1. & .572 & 2.4140 \\
\hline & $\begin{array}{l}\text { Degreased vegetable-tanned crust leather, } \\
\text { grain split. }\end{array}$ & .089 & 2. 0360 \\
\hline 4 & Obtained from area adjoining specimen 3 & $: 069$ & 0.9555 \\
\hline & $\begin{array}{l}\text { Degreased vegetable-tanned crust leather, } \\
\text { corium split. }\end{array}$ & .089 & 0.8985 \\
\hline & Obtained from area adjoining specimen $5 \ldots$ & .089 & 3.1540 \\
\hline & $\begin{array}{l}\text { Degreased vegetable-tanned crust leather, } \\
\text { flesh split. }\end{array}$ & .056 & 0.9920 \\
\hline 8 & Obtained from area adjoining specimen $7 \ldots$ & .056 & 1.9215 \\
\hline & $\begin{array}{l}\text { Corium split of raw hide, sample dehydrat- } \\
\text { ed by solvent exchange process. }\end{array}$ & .160 & 1.7225 \\
\hline 10 & $\begin{array}{l}\text { Corium split of raw hide, sample dehydrat- } \\
\text { ed by solvent exchange process, rewetted, } \\
\text { and evaporated. }\end{array}$ & .147 & 6.720 \\
\hline 11 & Vegetable-tanned shardskin from section & .290 & 2. 7780 \\
\hline & Obtained from area adjoining specimen 11 & .290 & 0.8745 \\
\hline & Vegetable-tanned sharkskin (Gata Shark)... & .394 & 1.8355 \\
\hline & Air-dried kangaroo tail tendon........... & & 17.4360 \\
\hline
\end{tabular}

skin was immersed in acetone, split, immersed in alcohol, and finally reimmersed in acetone and allowed to evaporate at room temperature and atmospheric conditions. Only the center portion of the corium was used. Specimen 10 was prepared by rewetting an adjoining portion of the hide prepared for specimen 9 and soaking it in water for a few hours. This rewet skin was then allowed to dry at room temperature.

Specimens 11 and 12 were from a soft, pliable sample of sharkskin obtained from a section along the backbone and near the head of a Night Shark. Specimen 13 was a sample of hard industrial shark leather used for shark-tipped uppers. It was obtained from a Nurse (Gata) Shark. All three of these sharkskin specimens were vegetable tanned.

Specimen 14 consisted of sections of air-dried kangaroo tail tendon.

\section{Apparatus and Procedure}

The experimental procedure consisted, essentially, in forcing a measurable quantity of mercury under a known pressure into a porous specimen. In general, the apparatus used is similar to that described by Ritter and Drake [7]. The specimen was placed in a calibrated glass dilatometer, illustrated in figure 1. A glass ball was placed above the specimen to prevent scorching during the sealing of the chamber. Changes in resistance of a wire shunted by the mercury column in a capillary tube were used to deter-

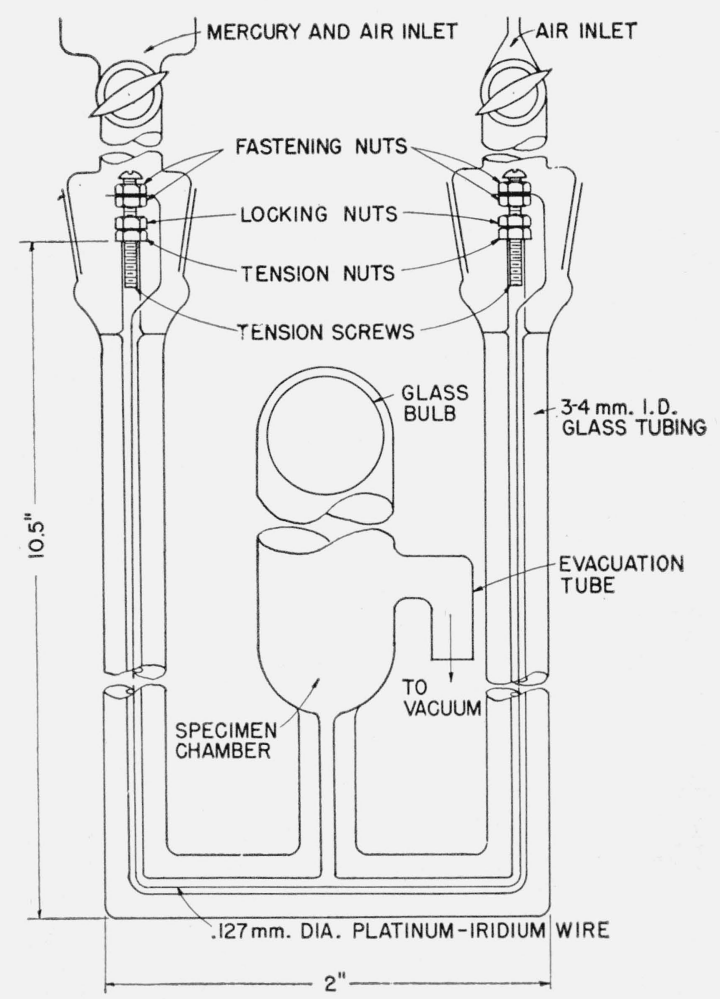

FIGURE 1. Schematic representation of the dilatometer. 
mine the quantity of mercury forced into the specimen. For this purpose a $0.127-\mathrm{mm}, 70$-percentplatinum-30-percent-iridium wire, recommended by Drake [13], was threaded into the capillary tube. The wire was clamped with the fastening nuts and stretched taut by adjusting the tension and locking nuts.

The dilatometer was calibrated by measuring changes in resistance of the wire for weighed increments of mercury metered out of the dilatometer through a stopcock to the evacuation tube. Straight lines were always obtained for these calibration curves, and duplicate calibrations demonstrated that using a new section of wire from the same spool did not significantly alter the calibration.

After the specimen was sealed in, the dilatometer was attached to a high-vacuum system by means of the evacuation tube. The caps were placed in the ground-glass joints, and the system was evacuated at a pressure of $10^{-5} \mathrm{~mm}$ of mercury for more than $4 \mathrm{hr}$. (In order to facilitate the removal of moisture, the specimens had been previously "dried" in open dishes overnight at $80^{\circ} \mathrm{C}$ in a forced-air oven.) The evacuation tube was then sealed off, separating the dilatometer, which was under vacuum, from the remainder of the system. The dilatometer was then filled with mercury by means of a stopcock. After filling the dilatometer with mercury, air was slowly admitted over the mercury columns through the stopcocks attached to the two caps, which were removed after this operation. The sizes of the specimens were, in general, so adjusted that the entire length of the dilatometer would be used in the pressure range studied.

The filled dilatometer was placed in a polyethylene bag and inserted into the high-pressure vessel in the assembly illustrated in figure 2 . The purpose of the polyethylene bag was to contain any spilled mercury and prevent amalgamation of the steel under pressure [14].

One end of the resistance wire was silver-soldered to the insulated piano-wire lead taken through the cap of the vessel, and the other end was silversoldered to a lead attached to the inner part of the vessel. After assembly, the apparatus was placed under a pressure of 50 psi and allowed to remain overnight before any measurements were carried out, in order to assure that equilibrium conditions of both temperature and mercury penetration were present. In the range below 50 psi, pressure measurements conducted without a specimen, but with mercury and a glass ball in the dilatometer, revealed an increase in resistance. This was probably the result of filling the capillary space between the glass ball and the wall of the dilatometer. For this reason, data obtained below 50 psi were not included. The measurements were carried out in a constant-temperature room maintained at $23^{\circ} \pm 2^{\circ} \mathrm{C}$. Changes in resistance were measured by a calibrated $\mathrm{G}-2$ Müeller bridge capable of producing measurements to $0.0001 \mathrm{ohm}$.

Pressure was applied in small increments, using commercial quality compressed nitrogen (see fig. 2). When the maximum pressure obtainable from the

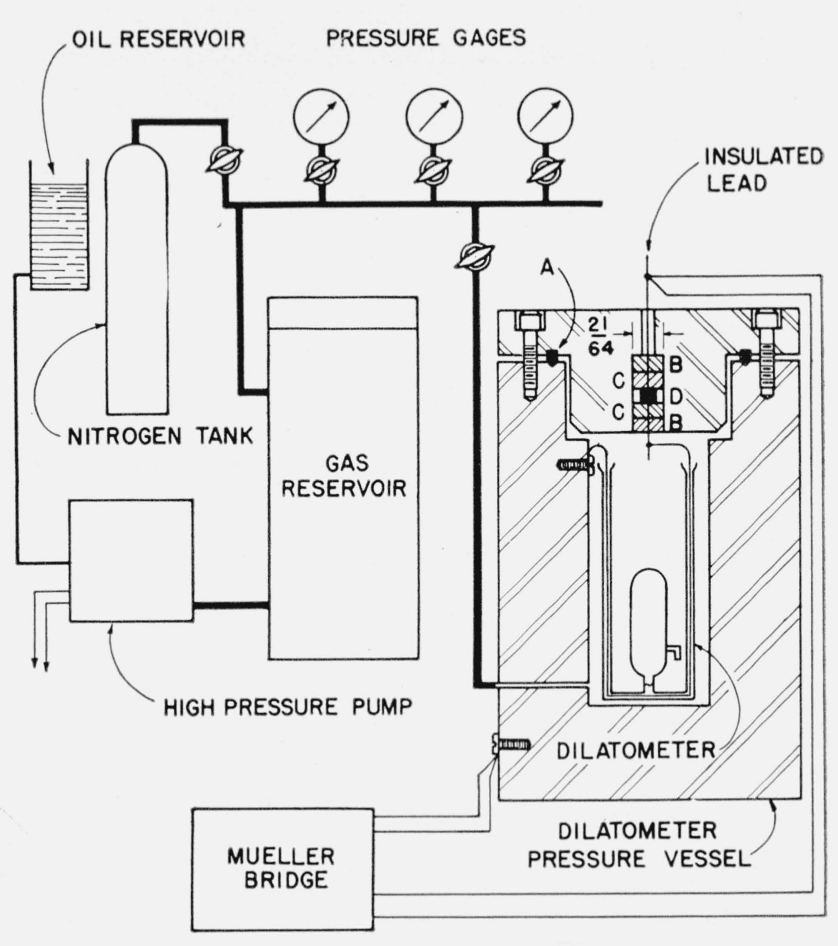

FIGURE 2. Schematic view of the assembled apparatus

A. Copper washer. B. Bakelite washers. C. Rubber washers (GR-M). D. Tool steel silver-soldered to wire.

nitrogen cylinder had been attained, the entire system was filled with nitrogen at about 2,000 -psi pressure. Higher pressures were attained through further compression of the gas by forcing oil into the gas reservoir with a high-pressure oil pump. The volume of the reservoir was such that at the maximum pressure, oil did not flow over the top of the dilatometer and form an insulating layer between the mercury and the resistance wire. The pressure gages were of the Bourdon type and calibrated against a dead-weight gage. Three gages were used: the first covered the range 0 to $300 \pm 1$ psi; the second, 250 to $3,000 \pm 10 \mathrm{psi}$; and the third, 2,500 to $10,000 \pm 50 \mathrm{psi}$. The pressures reported are the absolute pressures.

Time intervals of the order of $1 \mathrm{hr}$, depending somewhat upon the nature of the specimen and the amount of pressure, were required for attainment of equilibrium after each change of pressure. These resistance changes were not caused by thermal effects alone, as temperature differentials observed by shifting of the null point of the galvanometer were always dissipated in the course of a few minutes. This timelag was, therefore, attributed to the slow rate of penetration of mercury into the pores. Equilibrium was assumed after no change in resistance was detectable for periods of 15 to $30 \mathrm{~min}$. This was checked in a few experiments in which no significant change in resistance was observed after an additional period of $88 \mathrm{hr}$. 


\section{Results and Discussion}

\subsection{Pressure Curves}

Typical pressure curves are shown in figures 3 and 4. Although all the pressure curves appear to be of the same general form, there are considerable differences, both in location and slope of the pressure curves. The relatively long intervals necessary for establishment of equilibrium seem to indicate that penetration is not a rapid, straightforward process, but follows a rather slow, intricate path to reach pores in the inner part of the specimen. After porosimeter tests had been completed, the specimens had a gray appearance throughout their entire cross section, indicating uniform distribution of the mercury throughout the thickness of the specimen block.

The hysteresis encountered when the pressure was decreased in regular increments and allowed to come to equilibrium at each step is also demonstrated in figures 3 and 4 . At several stages in these experiments checks were made on the apparent equilibrium by allowing the pressure to remain unchanged for a period of $16 \mathrm{hr}$. No significant change in

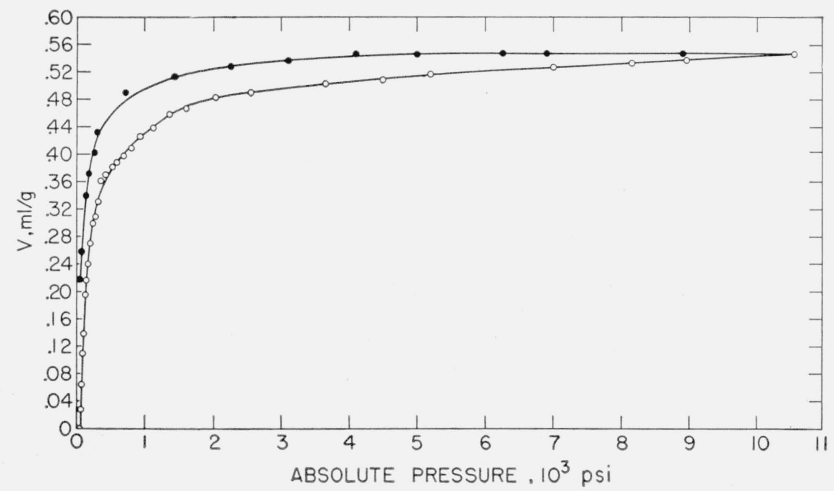

Figure 3. Increasing and decreasing pressure curves for flesh split of degreased vegetable-tanned crust leather, specimen 8.

$\mathrm{O}$, Increasing pressure; $\boldsymbol{\bullet}$, decreasing pressure.

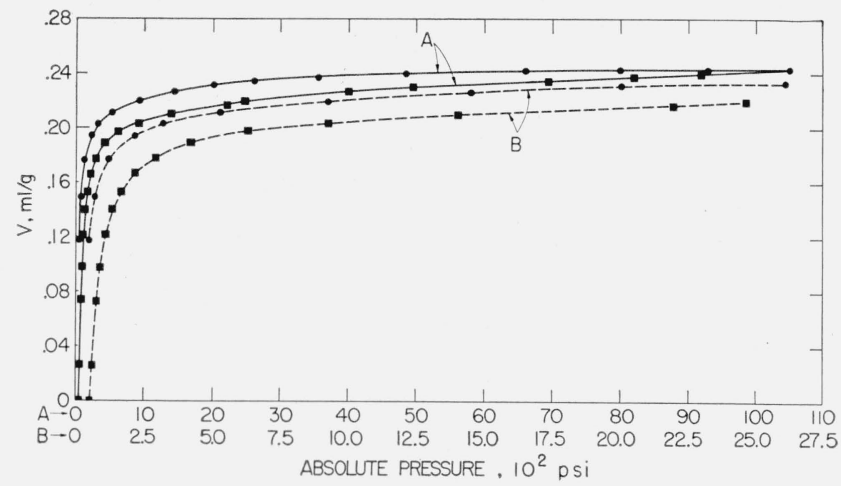

FIGURE 4. Increasing and decreasing pressure curves for raw hide dehydrated by solvent exchange, specimen 9.

Increasing pressure; $\mathbf{0}$, decreasing pressure; curves A, pressures to be read rom scale A; curves B, enlarged section of curves $A$, pressures to be read from scale $\mathrm{B}$. volume was noted. The increased transverse pressures developed when a moving column of mercury flows past a constriction in the pore diameter or through the neck of an "ink-well" type of pore are probably a contributing factor in breaking the continuity of the mercury column. Probably as a result of the large surface tension of mercury, it may be retained in pores of a radius smaller than would be indicated by the relation given in eq (1).

\subsection{Distribution Curves}

Distribution curves are shown in figures $5,6,7,8$, 9 , and 10. The distribution curve appears to be characteristic for each type of material. Specimens 1 and 2 were obtained from closely adjoining sections of finished sole leather, and have essentially the same pore-size distribution (fig. 5). Large variations are observed among the three splits reported (fig. 6). These split leathers were obtained from very closely adjoining areas and in some instances, actually from the same piece. Over the greater part of the range covered, the grain split contains the greatest volume of pores of all sizes, whereas the corium split contains the least total volume. This is confirmed by observations made on the amount of polyisobutylene (average molecular weight, 110,000) deposited in leather with and without the grain [15].

Specimen 9 was dehydrated by a solvent-exchange process, and specimen 10 was rewet and dehydrated by allowing the water to evaporate at room temperature. The difference between the two curves shown in figure 7 demonstrates that the solventexchange process leaves a more open but otherwise unchanged structure. The samples were different in physical appearance in that specimen 9 was soft and pliable and specimen 10, hard and inflexible. Although displaced, the two curves are fairly parallel. These observations are of interest for considerations of solvent-exchange drying techniques and freezedrying experiments. The small differences observed between the distribution curves for specimen 9 , the

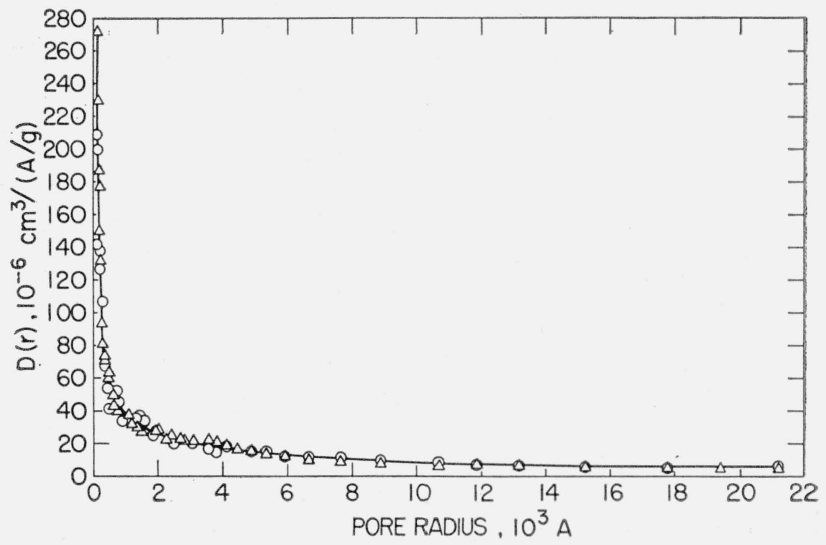

Figure 5. Distribution function in cubic centimeters of pore volume per angstrom of pore radius per gram of specimen vs pore radii for vegetable-tanned finished sole leather.

$\triangle$, Specimen $1 ; \bigcirc$, specimen 2 . 


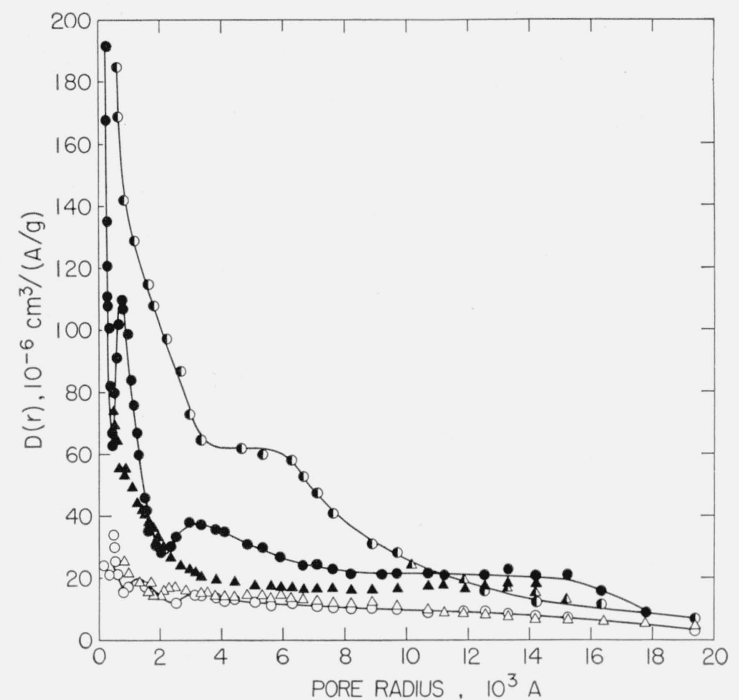

Figure 6. Distribution function vs pore radii for grain, corium and flesh splits of degreased vegetabletanned crust leathers.

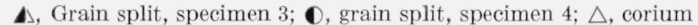
split, specimen 5; corium split, specimen 6 ; flesh split, specimen $7 ; 0$, flesh split, specimen 8.

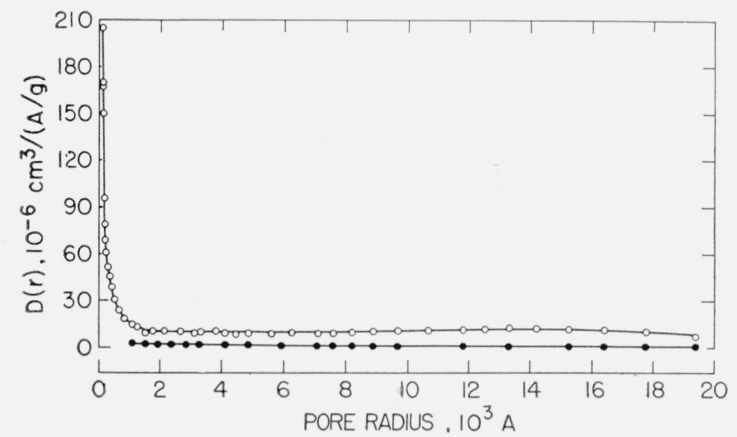

Figure 7. Distribution function vs pore radii for corium split of raw hide dehydrated by solvent exchange and by water evaporation.

$\mathrm{O}$, Solvent exchanged hide, specimen $9 ; \boldsymbol{\bullet}$, evaporated hide, specimen 10.

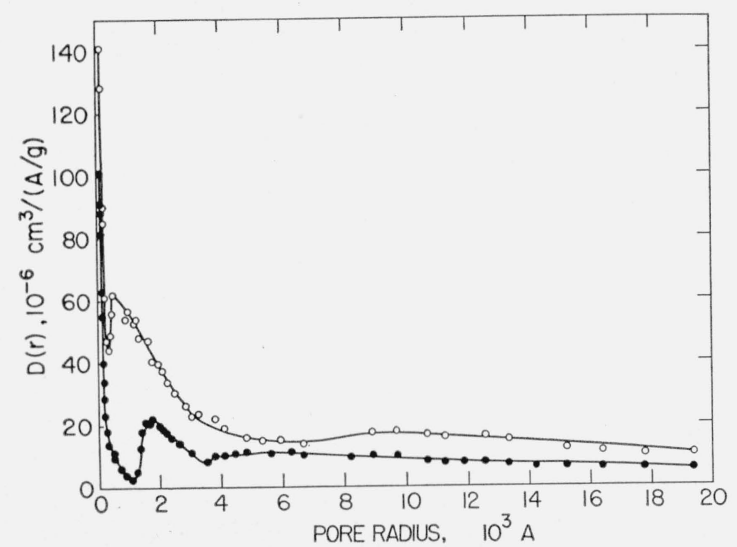

$326198-55-3$

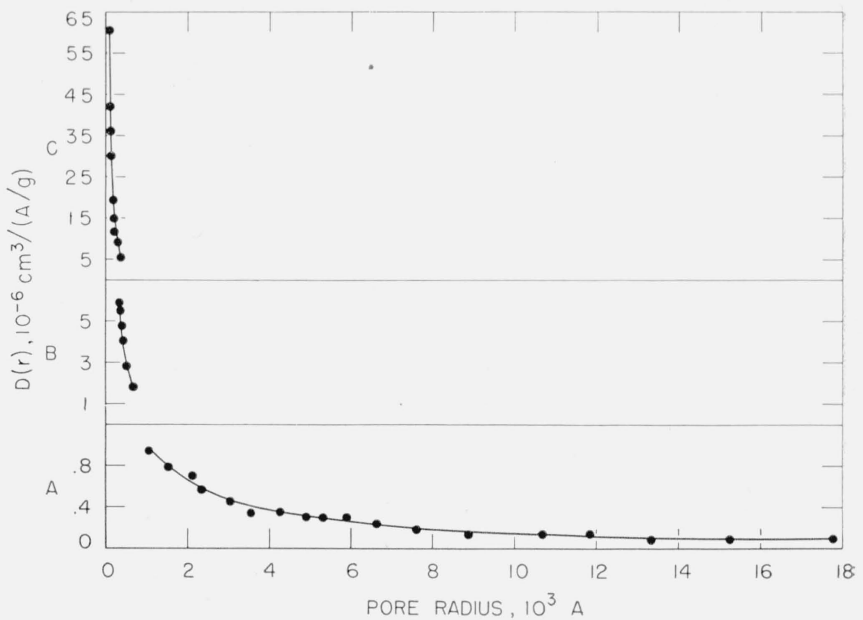

FIGURE 9. Distribution function vs pore radii for air-dried kangaroo tail tendon.

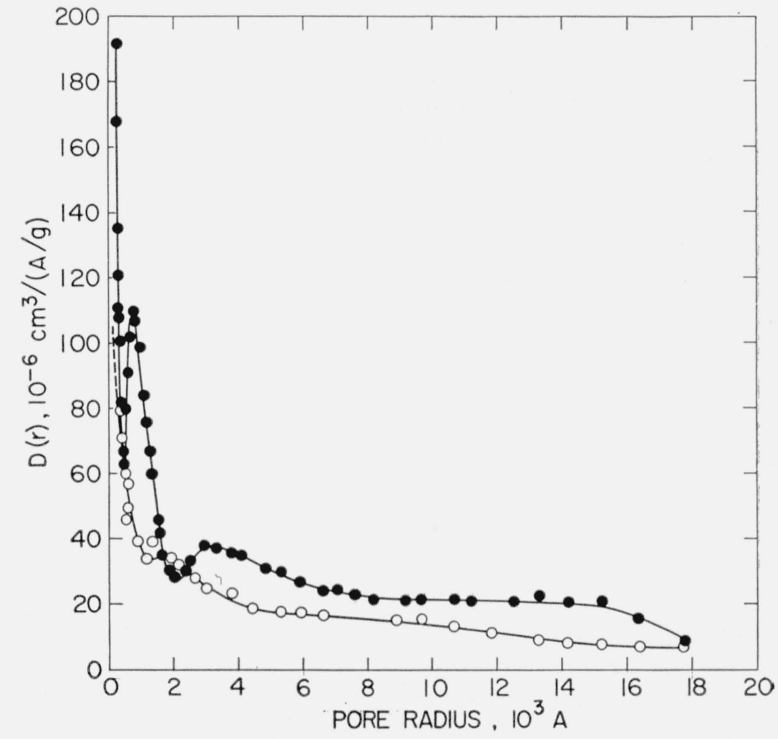

FIGURE 10. Distribution function vs pore radii for flesh split of degreased vegetable-tanned crust leather, specimen 8.

, Calculated from increasing pressure curve; $\bigcirc$, calculated from decreasing pressure curve.

FIGURE 8. Distribution function vs pore radii for vegetable-tanned sharkskin leathers.

O, Specimen $12 ; \bullet$, specimen 13. 
corium split of rawhide prepared by a solventexchange process, and specimen 6 , the corium split of tanned crust leather, indicate that the tanning process did not appreciably change the distribution of pore-size radii in the range 500 to $20000 \mathrm{~A}$.

Figure 8 shows curves obtained from sharkskin specimens 11, 12, and 13 . Except for the maximum points, these curves are of the same general shapes as the distribution curves from the other specimens.

The pore-size-distribution curve for kangaroo tail tendon for the range 18000 to $100 \mathrm{~A}$ in radius is given in figure 9. To make certain parts of the single curve more discernible, three different ordinate scales were used against a common abscissa. Part A represents the pore-size distribution from 18000 to $1000 \mathrm{~A}$; part B, from 800 to $350 \mathrm{~A}$; and part C, from 400 to $100 \mathrm{~A}$. As with the other materials, a significant volume and number of pores are concentrated in the size range 100 to $1000 \mathrm{~A}$ in radius. For example, in the case of kangaroo tail tendon (fig. 9), within the range 100 to $18000 \mathrm{~A}$ in pore radius, approximately 75 percent of the void volume was concentrated in pores ranging from 100 to 1000 $\mathrm{A}$ in radius and approximately 50 percent in pores ranging from 100 to $350 \mathrm{~A}$ in radius. On the other hand, in the case of specimen 12 , the flesh split of degreased vegetable crust leather (fig. 6), within the range 250 to $18000 \mathrm{~A}$ in pore radius, approximately 14 percent of the void volume was associated with pores ranging from 250 to $1000 \mathrm{~A}$ in radius and approximately 5 percent, with pores ranging from 250 to $500 \mathrm{~A}$.

All the distribution curves shown in figures 5 through 9 show a tendency to coincide at pore radii smaller than $1000 \mathrm{~A}$. This tendency increases with decreasing pore radii. It appears, therefore, that the majority of the volume occurrring in the range less than $1000 \mathrm{~A}$ in pore radius may be assigned to the inter- and intrafibril voids. The larger pores associated with the interfiber distances are probably much more dependent upon the source and previous history of the specimen than are the smaller pores associated with the inter- and intrafibril distances. In the transmission of water vapor, the mechanism would involve the small pores associated with the fine structure only to the extent to which they are connected by the large pore network. The distribution of the large pore system, therefore, provides a limiting factor in the "activated diffusion" [16] of water vapor throughout the porous matrix.

\subsection{Evaluation of Precision of Distribution Curves}

A statistical analysis of the distribution curves was made from the viewpoint of reliability. The equation used to determine standard deviations of selected points on the distribution curves was derived by applying the following principle [17]:

If $z=f(x, y, u, \cdots)$, where $x, y$, and $u$ are statistically independent variables (see footnote 2), then

${ }^{2}$ Independent in the statistical sense, i. e., having independent errors. Actually, $P$ and $\Delta P$ are not strictly independent. However, both of these quantually, $P$ and $\Delta P$ are not strictly independent. However, both of these quan-
tities are read from curves that fit the data very well. Consequently, their precision is likely to be better than that of actual measurements, and the derivation of the variance is likely to overestimate the true error.
$\operatorname{Var}(z) \cong(\partial f / \partial x)^{2} \operatorname{Var}(x)+(\partial f / \partial y)^{2} \operatorname{Var}(y)+\cdots$ Applying this to

$$
D(r)=(\Delta V / \Delta P) P^{2}[1 /(2 \sigma \cos \theta)],
$$

where $P, \Delta P$, and $\Delta V$ are the independent variables (see footnote 2), yields

$$
\sigma_{D(r)}^{2}=D(r)^{2}\left[\left(\frac{4}{P^{2}}+\frac{2}{(\Delta P)^{2}}\right) \sigma_{P}^{2}+\frac{2}{(\Delta V)^{2}} \sigma_{V}^{2}\right]
$$

where $\sigma_{D(r)}$ equals the standard deviation of the $D(r)$ values, $P$ equals the pressure, and $\Delta P$ and $\Delta V$ are the changes in pressure and volume, respectively, taken from the pressure curve in order to obtain the slope. Estimates of $\sigma_{P}$ and $\sigma_{V}$, the standard deviations of volume and pressure measurements, respectively, were obtained by assuming a rectangular distribution in the errors of $P$ and $V$ :

$$
\begin{aligned}
& =\frac{{\text { (range of uncertainty in pressure measurements })^{2}}_{12}}{12}=\frac{\text { (range of uncertainty in volume measurements) }^{2}}{12}
\end{aligned}
$$

The total pressure error was the largest interval of uncertainty involved in reading the pressure from the pressure curve. The total volume error was the largest interval of uncertainty involved in reading the volume of mercury from the pressure curve.

Table 2 lists estimates of the standard deviations for points on the distribution curves. These points were picked to give values for various portions of the curve over the rather wide pressure range, as well as for areas where the curves were undergoing some type of change in curvature.

The standard-deviation values should be regarded as an "order of magnitude" rather than as exact values. A smooth curve was drawn through the experimental data and used for the determination of the slope of the pressure curve. In some cases one value for $\sigma_{D(r)}$ is given, whereas in others, two values are listed. In the latter case, the two values are based on two different evaluations of the slope, $d V / d P$, by approximating it by a secant over a small portion of the pressure curve in the neighborhood of the point in question, or by using a large portion of the curve for the drawing of the secant. If a small portion is used, the uncertainty of the estimated slope due to experimental error is larger; if a large portion is used, this uncertainty is smaller, but an additional possibility of error is introduced by the assumption that the curve is essentially straight over a larger range. In all cases, a value of $\sigma_{D(r)}$ was computed on the basis of that value of the slope of the pressure curve used for the determination of $D_{(r)}$. In those cases where the pressure curve was visibly straight over a more extended region, a second value of $\sigma_{D(r)}$ was based upon a slope estimate of the pressure curve over this larger range. Although the first estimate is more conservative, it is 
TABLE 2. Standard deviations of typical $D(r)$ values

\begin{tabular}{|c|c|c|c|}
\hline Specimen & $r$ & $D(r)$ & $\sigma_{D(r)}$ \\
\hline No. 1. Finished sole leather...... & $\left\{\begin{array}{c}1 \\
13000 \\
2700 \\
2700 \\
1100 \\
1100 \\
410 \\
410 \\
130 \\
130\end{array}\right.$ & $\begin{array}{l}6.9 \times 10^{-6} \\
22.5 \\
22.5 \\
37.5 \\
37.5 \\
71 \\
71 \\
277 \\
277\end{array}$ & $\begin{array}{l}0.61 \times 10^{-} \\
5.7 \\
3.0 \\
2.8 \\
2.0 \\
12.3 \\
6.5 \\
26 \\
14\end{array}$ \\
\hline $\begin{array}{l}\text { No. 4. Grain split, degreased crust } \\
\text { leather. }\end{array}$ & $\begin{array}{r}16400 \\
5100 \\
5100 \\
970\end{array}$ & $\begin{array}{c}11.5 \\
62 \\
62 \\
136\end{array}$ & $\begin{array}{l}1 \\
3.4 \\
1.7 \\
9.8\end{array}$ \\
\hline $\begin{array}{l}\text { No. } 6 \text {. Corium split, degreased crust } \\
\text { leather. }\end{array}$ & $\left\{\begin{array}{r}16400 \\
2700 \\
670\end{array}\right.$ & $\begin{array}{r}7.4 \\
13.5 \\
19.2\end{array}$ & $\begin{array}{l}0.63 \\
3.5 \\
1.4\end{array}$ \\
\hline $\begin{array}{l}\text { No. } 8 \text {. Flesh split, degreased crust } \\
\text { leather. }\end{array}$ & $\left\{\begin{array}{r}16000 \\
4100 \\
590 \\
210 \\
210\end{array}\right.$ & $\begin{array}{l}16.2 \\
35 \\
91 \\
192 \\
192\end{array}$ & $\begin{array}{c}1.36 \\
1.1 \\
4.4 \\
16 \\
8.4\end{array}$ \\
\hline $\begin{array}{l}\text { No. 9. Corium split, solvent-ex- } \\
\text { changed raw hide. }\end{array}$ & $\left\{\begin{array}{r}16000 \\
5300 \\
4800 \\
2700 \\
970 \\
970 \\
970 \\
530 \\
530 \\
130\end{array}\right.$ & $\begin{array}{c}12 \\
9 \\
8.8 \\
10.6 \\
16.4 \\
16.4 \\
16.4 \\
31.9 \\
31.9 \\
150\end{array}$ & $\begin{array}{l}1.0 \\
0.6 \\
0.94 \\
1.6 \\
2.9 \\
2 \\
1.4 \\
4.5 \\
1.7 \\
7\end{array}$ \\
\hline $\begin{array}{l}\text { No. 10. Corium split, raw hide de- } \\
\text { hydrated by water evaporation. }\end{array}$ & $\left\{\begin{array}{r}15000 \\
1500\end{array}\right.$ & $\begin{array}{l}0.94 \\
2.36\end{array}$ & $\begin{array}{l}0.11 \\
0.32\end{array}$ \\
\hline No. 12. Sharkskin leather... & $\left\{\begin{array}{r}16000 \\
4800 \\
4800 \\
1100 \\
1100 \\
440 \\
440 \\
170\end{array}\right.$ & $\begin{array}{l}11.5 \\
15.9 \\
15.9 \\
54 \\
54 \\
68 \\
68 \\
91\end{array}$ & $\begin{array}{r}1.07 \\
2.8 \\
1.3 \\
5.6 \\
2.8 \\
13.8 \\
11.0 \\
7.3\end{array}$ \\
\hline No. 13. Sharkskin leather.... & $\left\{\begin{array}{r}16000 \\
4800 \\
1800 \\
1800 \\
670 \\
160 \\
120\end{array}\right.$ & $\begin{array}{r}6.3 \\
11.3 \\
22.3 \\
22.3 \\
9.6 \\
48 \\
82\end{array}$ & $\begin{array}{l}0.57 \\
0.69 \\
3.5 \\
2.4 \\
0.8 \\
3.1 \\
4\end{array}$ \\
\hline No. 14. Kangaroo tail tendon.... & $\left\{\begin{array}{r}15000 \\
2100 \\
140\end{array}\right.$ & $\begin{array}{l}0.092 \\
0.70 \\
34.6\end{array}$ & $\begin{array}{l}0.01 \\
0.07 \\
1.15\end{array}$ \\
\hline
\end{tabular}

believed that in those cases where a second estimate was computed, the latter is more likely to represent the true "order of magnitude" of the error.

The following specific conclusions concerning the distribution curves may be drawn from considering the $\sigma_{D(r)}$ data:

The $\sigma_{D(r)}$ values for specimen 1 demonstrate that the irregularities in the otherwise smooth curve are probably fluctuations due to experimental error and the only type of curve that is justified is a smooth one, as drawn in figure 5. Furthermore, although the uncertainty of the ordinate is considerably larger in the very small pore-size radii range, the slope of the curve is so large in this range that these $\sigma_{D(r)}$ values will not affect its general shape but merely influence the largest values observed. This curve can, therefore, within these limits, be regarded as a true representation of the pore-size distribution of this type of leather.

It is uncertain whether the flat portion of the distribution curve of the grain split of crust leather (specimen 4) shown in figure 6 occurring in the region of 5000-A pore radius is real or a result of experimental error. The shape of the curve in the region of the maxima and minima in the distribution curve of the flesh split (specimen 8) occurring in the vicinities of 500 and $2000 \mathrm{~A}$, respectively, does appear to be real, however. There is some doubt concerning the real nature of the dip occurring in this sample at about $2500 \mathrm{~A}$. With both the flesh and grain splits, the sharp fall in the curve at the very small poreradii range appears to be real. Whether the maxima and minima observed in these curves are typical for the types of material represented by these samples or are peculiar only to the particular specimens under study is unknown. The general shape and locations of these curves are, however, regarded as typical of the type of materials represented by the samples.

The pore-size distribution curve calculated from the decreasing pressure curve of a flesh split of degreased crust leather, specimen 8 , is shown in figure 10. Comparison is made with the distribution curve calculated from the increasing pressure curve for specimen 8. In comparing the two curves in figure 10 , the assumption is made that the structure of the material with respect to the mercury is the same, whether mercury is being forced into or withdrawn from the material. Furthermore, it is also assumed that the contact angle is the same for increasing and decreasing pressures. Such assumptions are necessary in view of the fact that no quantitative correction can be applied. The fact that the distribution curve obtained from decreasing pressure measurements does not retrace the distribution curve obtained from increasing pressure measurements may be partially accounted for by the known retention of mercury within the specimen after pressure had been reduced. From a measurement of the amount of mercury forced into specimen 8 between 55 and 10,550 psi and the amount of mercury recovered upon reduction of pressure to $49 \mathrm{psi}$, it appears that $0.217 \mathrm{ml}$ of mercury per gram of specimen was retained. This amount was approximately 40 percent of the pore volume explored between approximately 100 and $18,000 \mathrm{~A}$ in pore radius. Locations where this discrepancy is large, for example, the region of $750 \mathrm{~A}$ in pore radius, may be indications of significant numbers of pores with their entrances sealed off as a result of local nonhydrostatic pressure conditions. The discrepancies between these curves may also be indications of pores with entrance radii considerably different from the remainder of the pores (ink-well type pores). Some of the mercury retained as a result of either of the above causes probably is released at lower pressures. The crossing of the two curves in the region of $2,000 \mathrm{~A}$ in pore radius may be a result of the release of such a volume of mercury. The distribution curve obtained from decreasing pressure measurements was extrapolated from 350 to $100 \mathrm{~A}$, because the measurement of the slope of the decreasing pressure curve fell within the experimental error and $100 \mathrm{~A}$ corresponded to the maximum pressure attained. 
The $\sigma_{D(r)}$ values for the distribution curves, representing specimens 9 and 10 in figure 7 , show that the smooth curves drawn are justified and that the displacement of the two curves is real.

The sharp change in the direction of the distribution curve of specimen 12 shown in figure 8 , occurring in the vicinity of 200 to $500 \mathrm{~A}$ in pore radius, may not be real. This same type of change in slope and direction of slope occurs for specimen 13 and does appear to be real. It is possible that this type of pore-size distribution curve is typical for sharkskin, although these experiments are too limited to permit such a conclusion. It will be observed that both these curves very closely approach each other at very small pore-size radii.

The relatively small $\sigma_{D(r)}$ values obtained for the distribution curve of kangaroo tail tendon, specimen 14, would not significantly affect the general shape and location of the curve (fig. 9). Pore-size distribution curves obtained for three specimens of kangaroo tail tendon were completely reproducible.

\subsection{Comparison of "True" and Measured Distributions}

The pore-size distribution as measured by the porosimeter method may be compared with a mathematically random pore-size distribution in the manner of Meyer [18]. The porosimeter method may provide misleading information in the case of certain irregularities in the pore-size distribution. The socalled ink-well type of pore is an example where too small a portion of the pore volume is assigned to the large pores and too large a portion to the small pores. From probability considerations, Meyer [19] developed the following expression to correct the porosimeter data in an attempt to find the true pore distribution:

$\Gamma\left(r_{i}\right)=\sum_{K=1}^{i} \gamma_{K}=\sum_{K=1}^{i} \Theta_{K}\left[1-\sum_{K=1}^{i} a_{K} \prod_{L=0}^{i} \Psi_{K L} / \sum_{K=1}^{i} a_{K}\right]$

where $\Gamma_{i}$ is the fraction of volume filled with mercury at a known $r_{i}$ (experimental value), $\gamma$ is the injected differential fraction, $\theta$ is the corrected differential fraction, and

$$
\begin{aligned}
& a_{K}=\frac{f \Theta_{K}}{K r_{K}^{3}}, \\
& \Psi_{K L}=e^{-a} K^{V}\left(r_{K} r_{L}\right), \\
& \Psi_{i 0}=\left(1-\frac{A}{V} r_{i}\right) \text {, probability of pore not being } \\
& V\left(r_{K} r_{L}\right)=K\left(r_{L}+r_{K}\right)^{3}-K r_{K}^{3} .
\end{aligned}
$$

relates the value obtained for the quantity of mercury injected into the specimen, $\Gamma$, to a value, $\theta$, which would be anticipated from probability theory. This procedure can be applied to any predetermined number, $i$, of pore radii. Comparison can then be made between the injected differential fraction, $\gamma_{i}$ (existing between any two $i$ values) and the corrected differential fraction, $\theta_{i}$ (existing between the same two $i$ values).

Several corrected differential fractions were, therefore, calculated for samples that appeared to comply with the assumptions. The results are listed in table 3. Insofar as measurements were initiated on these samples at a pressure of 50 psi and a pore radius of $21000 \mathrm{~A}$, a comparison with the measured differential fraction of the first $i$ (pore radius at which comparison is made) value of the corrected differential fraction is meaningless and this value merely serves as a base point. The first $i$ value should, however, be an indication of the volume of pores neglected by starting measurements at 50 rather than at 0 psi. For example, a comparison of the $\gamma_{1}$ (injected differential fraction) and $\theta_{1}$ (corrected differential fraction) values in table 3 shows that a. larger pore volume appears to have been neglected for specimen 9 than for specimen 4 . There are several instances where the values of $\gamma$ are larger

\begin{tabular}{|c|c|c|c|c|c|c|}
\hline Specimen & $i$ & $P$ & $r$ & $\begin{array}{c}\text { Frac- } \\
\text { tion of } \\
\text { volume } \\
\text { filled } \\
\text { with } \\
\text { mer- } \\
\text { cury, } \\
\Gamma\end{array}$ & $\begin{array}{c}\text { Injected } \\
\text { differ- } \\
\text { ential } \\
\text { frac- } \\
\text { tion, } \\
\gamma\end{array}$ & $\begin{array}{l}\text { Cor- } \\
\text { rected } \\
\text { differ- } \\
\text { ential } \\
\text { frac- } \\
\text { tion, } \\
\Theta\end{array}$ \\
\hline $\begin{array}{l}\text { No 4. Grain split of de- } \\
\text { greased crust leather. }\end{array}$ & $\left\{\begin{array}{l}1 \\
2 \\
3 \\
4 \\
5\end{array}\right.$ & $\begin{array}{r}p s i \\
100 \\
200 \\
500 \\
1,000 \\
2,000\end{array}$ & \begin{tabular}{r}
\multicolumn{1}{c}{$A$} \\
10670 \\
5335 \\
2133 \\
1067 \\
533
\end{tabular} & $\begin{array}{r}0.11 \\
.31 \\
.51 \\
.62 \\
.69\end{array}$ & $\begin{array}{r}0.11 \\
.20 \\
.20 \\
.11 \\
.07\end{array}$ & $\begin{array}{r}0.19 \\
.16 \\
.16 \\
.11 \\
.07\end{array}$ \\
\hline $\begin{array}{l}\text { No. } 8 . \text { Flesh split of de- } \\
\text { greased crust leather. }\end{array}$ & $\left\{\begin{array}{l}1 \\
2 \\
3 \\
4 \\
5 \\
6 \\
7 \\
8\end{array}\right.$ & $\begin{array}{r}100 \\
200 \\
500 \\
1,000 \\
2,000 \\
4,000 \\
8,000 \\
10,000\end{array}$ & $\begin{array}{r}10670 \\
5335 \\
2133 \\
1067 \\
533 \\
267 \\
133 \\
107\end{array}$ & $\begin{array}{l}.20 \\
.36 \\
.50 \\
.57 \\
.64 \\
.67 \\
.71 \\
.73\end{array}$ & $\begin{array}{l}.20 \\
.16 \\
.14 \\
.06 \\
.07 \\
.03 \\
.04 \\
.02\end{array}$ & $\begin{array}{l}.30 \\
.14 \\
.08 \\
.05 \\
.07 \\
.03 \\
.04 \\
.02\end{array}$ \\
\hline $\begin{array}{l}\text { No. 9. Corium split of } \\
\text { solvent exchanged raw } \\
\text { hide. }\end{array}$ & $\left\{\begin{array}{l}1 \\
2 \\
3 \\
4 \\
5 \\
6 \\
7 \\
8\end{array}\right.$ & $\begin{array}{r}100 \\
200 \\
500 \\
1,000 \\
2,000 \\
4,000 \\
8,000 \\
10,000\end{array}$ & $\begin{array}{r}10670 \\
5335 \\
2133 \\
1067 \\
533 \\
267 \\
133 \\
107\end{array}$ & $\begin{array}{l}.26 \\
.39 \\
.46 \\
.49 \\
.51 \\
.54 \\
.56 \\
.58\end{array}$ & $\begin{array}{l}.26 \\
.12 \\
.07 \\
.03 \\
.02 \\
.03 \\
.02 \\
.01\end{array}$ & $\begin{array}{c}.41 \\
.13 \\
.04 \\
.01 \\
. .- \\
. . \\
. .-\end{array}$ \\
\hline $\begin{array}{l}\text { No. 6. Corium split of de- } \\
\text { greased crust leather. }\end{array}$ & $\left\{\begin{array}{l}1 \\
2 \\
3 \\
4 \\
5 \\
6\end{array}\right.$ & $\begin{array}{r}100 \\
200 \\
500 \\
1,000 \\
2,000 \\
4,000\end{array}$ & $\begin{array}{r}10670 \\
5335 \\
2133 \\
1067 \\
533 \\
267\end{array}$ & $\begin{array}{l}.17 \\
.30 \\
.41 \\
.45 \\
.47 \\
.49\end{array}$ & $\begin{array}{l}.17 \\
.13 \\
.10 \\
.04 \\
.02 \\
.02\end{array}$ & $\begin{array}{l}.31 \\
.13 \\
.04 \\
.02 \\
.-. \\
. . .\end{array}$ \\
\hline
\end{tabular}
than the corresponding values of $\theta$. Such a result may mean that pores that have been measured in the pore-size range corresponding to the $i$ value under consideration actually belong in a larger pore-size range, that is, at a lower value of $i$. For example, the fact that the value of $\gamma_{2}(0.20)$ is larger

TABLE 3. Comparison of corrected with injected volume fractions 
than the corresponding value of $\theta_{2}(0.16)$ for specimen 4 may mean that some of the pores, constituting the measured volume from which the differential fraction $\gamma_{2}$ is obtained, actually should have been measured at a lower pressure and added to $\gamma_{1}$. The ink-well type of pore could be an example of such a pore. In the case of several $i$ values for specimens 6 and 9, the values of $\theta$ approached zero, and are omitted from table 3.

One of the basic assumptions made in deriving Meyer's relationship was that a randomness of pore distribution exists. This appears to be a valid assumption for a relatively thin split of leather or collagenous tissue. It is not true for an unsplit piece of hide, as there appears to be considerable differences in pore-size distribution existing among the different splits (fig. 6). In the case of air-dried kangaroo tail tendon, where the fibers were highly oriented about a common axis, the application of this relationship gave meaningless results. Although these assumptions may not be completely valid for the materials studied here, they appear to be justified as a first approximation. It should be pointed out, however, that this treatment must be applied to many more specimens and materials before the results obtained can be fully evaluated.

The author welcomes this opportunity to express his sincere appreciation to several members of the National Bureau of Standards: to Charles E. Weir for suggestions regarding both the design of the equipment and the interpretation of the data, to John Mandel for the derivation of the equation used to determine the standard deviations, and to Max Swerdlow for valuable discussions and suggestions in reporting this work.

\section{References}

[1] T. J. Carter and J. R. Kanagy, A flex tension test for leather, J. Am. Leather Chemists' Assoc. 49, 23 (1954).

[2] J. R. Kanagy and E. L. Wallace, Density of leather and its significance, J. Research NBS 31, 169 (1943) RP1556.
[3] J. R. Kanagy, Adsorption of water vapor by untanned hide and various leathers at $100^{\circ} \mathrm{F}$, J. Research NBS 38, 119 (1947) RP1763; J. Am. Leather Chemists' Assoc. 42, 98 (1947).

[4] J. R. Kanagy, Influence of temperature on the adsorption of water vapor by collagen and leather, J. Research NBS 44, 31 (1950) RP2056; J. Am. Leather Chemists' Assoc. 45, 12 (1950).

[5] M. Swerdlow and R. R. Stromberg, Collagen pores determined by electron microscopy, J. Research NBS $\mathbf{5 4}$, 83 (1955) RP 2568.

[6] E. W. Washburn, The dynamics of capillary flow, Phys, Rev. 17, 273 (1921).

[7] H. L. Ritter and L. C. Drake, Pore size distribution in porous materials. I. Pressure porosimeter and determination of complete macropore-size distributions, Ind. Eng. Chem., Anal. Ed. 17, 782 (1945).

[8] L. C. Drake and H. L. Ritter, II. Macropore-size distributions in some typical porous substances, Ind. Eng. Chem., Anal. Ed. 17, 787 (1945).

[9] A. J. Juhola and E. O. Wiig, Pore structure in activated charcoal. II. Determination of macro pore size distribution, J. Am. Chem. Soc. 71, 2078 (1949).

[10] L. G. Joyner, E. P. Barrett, and R. Skold, The determination of pore volume and area distributions in porous substances. II. Comparison between nitrogen isotherm and mercury porosimeter methods, J. Am. Chem. Soc. 73, 3155 (1951).

[11] E. P. Barrett, L. G. Joyner, and P. P. Halenda, The determination of pore volume and area distributions in porous substances. I. Computations from nitrogen isotherms, J. Am. Chem. Soc. 73, 373 (1951).

[12] Federal Specification KK-L-311a, Leather; Methods of Sampling and Testing, Method 1021 (Jan. 19, 1953).

[13] L. C. Drake, Pore-size distribution in porous materials. Application of high pressure mercury porosimeter to cracking catalysts, Ind. Eng. Chem. 41, 780 (1949)

[14] P. W. Bridgman, The physics of high pressure (G. Bell and Sons, Ltd., London, England, 1949).

[15] R. Oehler, National Bureau of Standards (private communication).

[16] J. R. Kanagy and R. A. Vickers III, Factors affecting the water-vapor permeability of leather. $J$. Research NBS 44, 347 (1950) RP2082; J. Am. Leather Chemists' Assoc. 45, 211 (1950).

[17] C. A. Bennett and N. L. Franklin, Statistical analysis in chemistry and the chemical industry, p. 51 (John Wiley and Sons, Inc., New York, N. Y., 1954).

[18] H. I. Meyer, Pore distribution in porous media, J. Appl. Phys, 24, 510 (1953)

[19] H. I. Meyer, United Gas Corporation, Shreveport, La. (private communication, Feb. 1954).

Washington, August 2, 1954. 